\title{
CANDIDO, SANTIAGO E A MACUMBA: POSSÍVEIS LEITURAS DA "DIALÉTICA DA MALANDRAGEM” E DO “ENTRE-LUGAR DO DISCURSO LATINO- AMERICANO” DENTRO DO CAPÍTULO “MACUMBA”, DE MACUNAÍMA
}

\author{
CANDIDO, SANTIAGO AND MACUMBA: POSSIBLE READINGS OF THE \\ “DIALÉTICA DA MALANDRAGEM” AND “ENTRE-LUGAR DO DISCURSO LATINO- \\ AMERICANO” IN THE CHAPTER “MACUMBA”, OF MACUNAÍMA
}

Luis Eduardo Veloso Garcia ${ }^{1}$

\section{Resumo}

Abordaremos neste artigo uma leitura significativa das ideias presentes em "Dialética da Malandragem”, de Antônio Candido, e "O Entre-Lugar do Discurso Latino-Americano", de Silviano Santiago, contextualizando-as através de uma proposta prática de convergência destes dois textos teóricos dentro do mesmo texto, mais especificamente o capítulo "Macumba”, do livro Macunaíma, de Mario de Andrade. Portanto, ao retratar a importância destes textos e colocá-los no mesmo espaço interpretativo, pretende-se aqui não só a compreensão dos conceitos refletidos neles, mas também sua exemplificação como modelo interpretativo crítico de nossa cultura.

Palavras-chave: critica literária, Silviano Santiago, Antonio Candido, Macunaíma.

\begin{abstract}
We will approach in this article a meaningful reading of the ideas found in "Dialética da Malandragem", by Antonio Candido, and "O Entre-Lugar do Discurso Latino-Americano", by Silviano Santiago, contextualizing these ideas through of a practical proposal of convergence of these two theoretical texts within the same text, more specifically the chapter "Macumba", of the book Macunaíma, by Mario de Andrade. Therefore, portraying the importance of these texts and putting in the same interpretative space, it is intended here not only understanding the concepts reflected in these, but also its exemplification as critical interpretive model of our culture.
\end{abstract}

Keywords: Literary criticism, Silviano Santiago, Antonio Candido, Macunaíma.

\footnotetext{
${ }^{1}$ Mestre em Estudos Literários pela Universidade Estadual de Londrina - UEL (Londrina - PR)./ Especialista em Estudos Linguísticos e Literários pela Universidade Estadual do Norte do Paraná - UENP (Jacarezinho PR). E-mail: dinhopiraju@gmail.com
} 


\section{A dialética da malandragem}

Neste ensaio de 1970, publicado na Revista do Instituto Estudos Brasileiros, Antônio Candido apresenta uma análise inovadora do romance Memórias de um Sargento de Milícias (1855), de Manuel Antônio de Almeida, instaurando uma linha até então inédita para a nossa teoria literária: a linha da malandragem .

Para isso, o autor parte de uma avaliação detalhada da personagem principal do romance, Leonardo Pataca, mostrando que tal protagonista não pertence diretamente à linhagem picaresca, como tanto ele em sua Formação da Literatura Brasileira em 1959 mais precisamente no texto "O Romance em Moto-Contínuo" - quanto outros autores como José Veríssimo, Mário de Andrade e Josué Montello afirmavam anteriormente.

Aqui, Candido apontará que essa construção, na verdade, apresenta mais divergências do que similaridades com a tradição picaresca, assinalando alguns exemplos, como:

- a diferença entre os focos narrativos, sendo na maioria das vezes em primeira pessoa no caso dos pícaros, criando assim seu tom de depoimento pessoal, e em Memórias de um Sargento de Milícias, através de um narrador que não participa da ação;

- no caso do pícaro, valem-se sempre da astúcia para obter algum beneficio em troca, em compensação, o malandro, muitas vezes pode praticar picardias pelo simples prazer do jogo, fortalecendo sua imagem de aventureiro, astucioso, comum a vários folclores;

- as experiências pelas quais passam os pícaros transformam-se ao final das histórias em aprendizagem, diferentemente do malandro, que não modifica seu modo de agir em momento algum, a não ser para seu bel-prazer.

Após tais considerações, Candido instaura a corrente das obras que abordam a temática da malandragem, compreendendo, então, Leonardo Pataca como:

\footnotetext{
o primeiro grande malandro que entra na novelística brasileira, vindo de uma tradição quase folclórica e correspondendo, mais do que se costuma dizer, a certa atmosfera cômica e popularesca de seu tempo, no Brasil. Malandro que seria levado à categoria de símbolo por Mário de Andrade em Macunaíma e que Manuel Antônio com certeza plasmou espontaneamente. (CANDIDO, 1970, p. 71)
}

Através da definição desta linha de pensamento sobre o malandro, Candido introduz a ideia que leva o título do ensaio, da qual traz uma observação muito interessante do modo de ser brasileiro a partir da dinâmica social: a dialética da malandragem.

Refletida através da relação entre o movimento histórico e social da diversidade cultural brasileira na sociedade joanina do Rio de Janeiro que permeia o romance de Manuel 
Antônio de Almeida, o autor mostra no texto certa falta de julgamento de valores que respaldem a formação de uma ordem clara, valores estes sempre relacionados aos esforços de uma organização social e de ideologias que a justificam, entre eles:

a existência objetiva e o valor real de pares antiéticos, entre os quase é preciso escolher, e que significam lícito ou ilícito, verdadeiro ou falso, moral ou imoral, justo ou injusto, esquerda ou direita política e assim por diante. Quanto mais rígida a sociedade, mais definido cada termo e mais apertada a opção. (CANDIDO, 1970, p. 84)

Justamente nesta falta de valores que se instaura então a dialética da malandragem, conhecida também como a dialética da ordem e da desordem, numa nuance da qual as duas frentes convivem no mesmo espaço sem uma separação visível, tanto a classe aristocrata quanto a classe pobre convivem no mesmo âmbito, entre arranjos e acomodações, sem levar o símbolo regente da moral tão forte na formação de outras sociedades consideradas de primeiro mundo, como a norte-americana, no exemplo usado por Candido.

Por isso, o romance Memórias de um Sargento de Milícias acaba cumprindo perfeitamente o papel de retratar o movimento daquela sociedade, não com a pretensão realista, como frisa Candido, mas em suas nuances mais profundas, nos costumes, como se vê nesta citação:

Pelo que vimos, o princípio moral das Memórias parece ser, exatamente como os fatos narrados, uma espécie de balanceio entre o bem e o mal, compensados a cada instante um pelo outro sem jamais aparecerem em estado de inteireza. Decorre a idéia de simetria ou equivalência, que, numa sociedade meio caótica, restabelece incessantemente a posição por assim dizer normal de cada personagem. Os extremos se anulam e a moral dos fatos é tão equilibrada quanto as relações dos homens. (CANDIDO, 1970, p. 85)

Portanto, ao conseguir expor tal pensamento, Candido consegue também, como nos chama a atenção Luiz Carlos Jackson, estabelecer de modo sistemático as principais diretrizes de uma abordagem preocupada em "levar em conta a dimensão da sociedade sem fazer crítica sociológica, mostrando efetivamente (não apenas postulando teoricamente) a sublimação dos dados sociais e psicológicos em estrutura estética” (JACKSON, 2002, p. 129).

\section{O entre-lugar do discurso latino-americano}


Presente no livro Uma Literatura nos Trópicos (1978), o ensaio “O Entre-Lugar do Discurso Latino-Americano”, escrito precisamente em 1971 pelo poeta, professor, tradutor, ensaísta, crítico literário e cinematográfico Silviano Santiago, apresenta uma das mais conhecidas teorias sobre o posicionamento da literatura (e da cultura em geral) latinoamericana diante da crítica especializada praticada por aqui.

Segundo o autor, temos na ideia de entre-lugar a preocupação referente ao lugar incerto entre duas posições discursivas do qual a enunciação latino-americana se encontra, entre o peso da posição dominante e a negação direta desta.

Baseando-se, então, o pensamento de entre-lugar no espaço articulador dos Estudos Culturais, que pode alargar seus conceitos e noções ao emprestar premissas de outras disciplinas, entre elas Filosofia, Sociologia, História, Geografia, Etnologia, etc, Santiago constrói tal teoria a partir das ideias de três grandes pensadores do século XX: Michel Foucault, Jacques Derrida e Oswald de Andrade.

Com Foucault e Derrida, temos as noções de deslocamento, descentralização, desconstrução - este último o termo chave cunhado por Derrida que vai influenciar fortemente a geração de Silviano Santiago - como peças fundamentais para o entendimento desta teoria, sendo elas baseadas num pensamento mais sutil, do qual o tirar ou mudar de lugar, ser contrário a um determinado centro e a uma determinada construção não pode ser encarado pelo viés da negativa simplesmente, mas sim da visibilidade, reforçando a ideia de lugar, centro e construção, num jogo de discurso que só consegue ser alcançado no realce de seu termo originador.

Partindo para a teoria cultural, Santiago coloca então o desconstrutivismo de Derrida como principal fonte de sua teoria, definindo-o da seguinte forma no Glossário de Derrida (1976), obra em que faz um mapa de leitura dos termos do filosofo francês:

\footnotetext{
Operação que consiste em denunciar num determinado texto (o da filosofia ocidental) aquilo que é valorizado e em nome de quê e, ao mesmo tempo, em desrecalcar o que foi estruturalmente dissimulado nesse texto. A leitura desconstrutora da metafísica ocidental se apresenta como a discussão dos pressupostos, dos conceitos dessa filosofia, e portanto a denúncia de seu alicerce logo-fono-etnocêntrico. Apontar o centramento é mostrar aquilo que é "relevado" no texto da filosofia; apontar o que foi recalcado e valorizá-lo é a fase do reversement (inversão), pois estaria apenas deslocando o centro por inversão, quando a proposição radical é a anulação do centro como lugar fixo e imóvel. (SANTIAGO, 1976, p. 17)
} 
Além do desconstrutivismo, temos outro influenciador direto usado como suporte do entre-lugar: o pensamento antropofágico, instaurado por Oswald de Andrade, junto com os modernistas de 22.

Através do raciocínio da assimilação de virtudes culturais e descarte de valores estéreis e ultrapassados, típicos da Europa colonialista/neocolonialista, Oswald torna-se não só a legítima tradução do que buscava Derrida, mas também um importante objeto para que a teoria de Santiago ganhe sua completude, com uma voz representante direta da América Latina.

Entre as contribuições relevantes do pensamento antropofágico, o ensaísta chama atenção para a destruição sistemática dos conceitos de unidade e de pureza, usando como exemplo uma citação símbolo deste discurso do próprio Oswald de Andrade no significativo artigo "Sol da Meia Noite” (1945):

\begin{abstract}
A Alemanha racista, purista e recordista precisa ser educada pelo nosso mulato, pelo chinês, pelo índio mais atrasado do Peru ou do México, pelo africano do Sudão. É preciso ser misturada de uma vez para sempre. Precisa ser desfeita no melting pot do futuro. Precisa mulatizar-se. (ANDRADE, 1972, p. 62)
\end{abstract}

Ao recriminar, portanto, o esforço da crítica literária em sempre procurar o valor das obras lançadas na America Latina dentro das fontes e influências emanadas dentro do texto por outras escolas literárias, fazendo destas obras parasitas em que a imitação e a dívida tornam-se o único julgamento de valor, Silviano Santiago consegue aqui propor a tarefa de um novo discurso crítico baseado na destruição destes conceitos, do qual o entre-lugar representará uma busca por respeito pela cultura criada neste espaço, num exercício dialético formado entre:

\footnotetext{
O sacrifício e o jogo, entre a prisão e a transgressão, entre a submissão ao código e a agressão, entre a obediência e a rebelião, entre a assimilação e a expressão - ali, nesse lugar aparentemente vazio, seu templo e seu lugar de clandestinidade, ali, se realiza o ritual antropofágico da literatura americana. (SANTIAGO, 2000, p. 26)
}

\title{
3. Proposta de leitura
}

Explicado o que sustenta os conceitos, buscaremos agora uma leitura possível da “Dialética da Malandragem”, de Candido, e do "Entre Lugar do Discurso Latino-Americano”, de Santiago, dentro do capítulo “Macumba”, presente no livro Macunaíma (1928), de Mario de Andrade. 
Em Antonio Candido, apontaremos como o movimento social baseado na articulação da ordem e da desordem ocorre de forma clara e concisa no capítulo, representando a sociedade embrionária do nascimento do samba.

No termo de Silviano Santiago, buscaremos posicionar neste capítulo o discurso da valorização do samba presente na ação de Macunaíma contra seu inimigo Venceslau Pietro Pietra, na desconstrução consolidada por um objeto da cultura nacional que consegue fazer frente à cultura colonialista/neocolonialista na obra. Vamos, então, para as análises.

\section{Leituras possíveis da “Dialética da Malandragem” no capítulo “Macumba”}

No ensaio “Dialética da Malandragem”, Antônio Candido deixa claro que o pensamento de Manuel Antônio de Almeida alcançaria sua completude na obra Macunaíma (1928), de Mario de Andrade, relativizando a importância deste marco modernista, que consegue elevar a figura mítica do malandro ao status simbólico.

Explicando resumidamente o capítulo, nosso herói Macunaíma vai para o Rio de Janeiro pedir a uma mãe de santo que castigue seu inimigo Venceslau Pietro Pietra, conseguindo alcançar o que tanto almeja através da prática da macumba. Nesta prática, veremos o retrato de uma cena extremamente representativa para a nossa cultura, não baseada em lendas e mitos folclóricos como ocorre nos outros capítulos da obra, mas em personagens reais de nossa cultura que frequentavam constantemente o terreiro do qual nasce um dos mais fortes símbolos de identidade brasileira: o samba.

Entre os personagens, é preciso destacar dois importantes nomes para o entendimento do capítulo:

- a figura central da mãe de santo Tia Ciata, conhecida também como a "Madrinha do Samba”, pois justamente em seu terreiro foi composto o considerado primeiro samba da história, "Pelo Telefone” (1916), de Donga e Mauro de Almeida;

- o "ogã tocador de atabaque filho de Ogum, bexiguento e fadistas de profissão", modo excêntrico que Mario de Andrade escolheu para nomear dentro da obra seu amigo Pixinguinha, sem dúvida nenhuma o maior nome do choro nacional, com direito a piada com sua bochecha grande. Além de frequentador assíduo do terreiro de Tia Ciata, foi ele quem descreveu como funciona o ritual do candomblé conhecido popularmente como "macumba" para o autor de Macunaíma. 
Temos, então, retratado aqui o espaço embrionário do samba, espaço este capaz de representar muito bem a movimentação social do Rio de Janeiro das primeiras décadas do século XX.

Candido diz em sua análise da obra Memórias de um Sargento de Milícias que o movimento da sociedade joanina não se apresenta como separatório, pois a percepção das relações humanas tomadas em conjunto no país constrói-se fora de um lugar fixo, fazendo com que as classes que se distanciam monetariamente acabem por interagir simultaneamente, numa nuance da qual classe aristocrata e classe pobre convivam no mesmo ambiente.

Nesta interação sem complexos ou julgamentos incisivos de valores que se instaura a dialética da malandragem, ou da ordem e da desordem, e, na compreensão deste espaço, vemos seu reflexo na cena da macumba, da qual várias marcações servirão de exemplo, entre elas, as referências das representações trabalhistas que convivem no terreiro dividindo o mesmo ritual, sem preferência ou diferenciação entre o ato, como percebemos nesta citação:

\footnotetext{
Vai, um rapaz filho de Ochum, falavam, filho de Nossa Senhora da Conceição cuja macumba era em dezembro, distribuiu uma vela acesa pra cada um dos marinheiros marcineiros jornalistas ricaços gamelas fêmeas empregados-públicos, muitos empregados-públicos! todas essas gentes e apagou o bico de gás alumiando a saleta. $\mathrm{E}$ então seguiam advogados taifeiros curandeiros poetas o herói gatunos portugas senadores, todas essas gentes dançando e cantando a resposta da reza. (ANDRADE, 2008, p. 61-62)
}

Ou nesta também:

Toda a gente vendedores bibliófilos pés-rapados acadêmicos banqueiros, todas essas gentes dançando em volta da mesa cantavam [...] Os ladrões os senadores os jecas os negros as senhoras os futebóleres, todos, vinham se rojando por debaixo do pó alaranjando a saleta e depois de batida a cabeça com o lado esquerdo no chão, beijavam os joelhos beijavam todo o corpo do uamoti. (ANDRADE, 2008, p. 64-66)

Para reafirmar com propriedade as aproximações ocorridas no espaço retratado, podemos destacar o modo que Mario de Andrade trabalha a vírgula quando cita as profissões e funções sociais, tirando-a para caracterizar a proximidade destas quando colocadas dentro de um local como o terreiro citado.

Além das referências de funções trabalhistas, Mario de Andrade cria neste capítulo outro trecho muito importante para a compreensão desta movimentação social, colocando no mesmo local grandes intelectuais defensores de nossa cultura popular e os maiores malandros da década de 20, todos estes, frequentando o terreiro de Tia Ciata em plena harmonia, como podemos perceber no parágrafo final do capítulo: 
E pra acabar todos fizeram a festa juntos comendo bom presunto e dançando um samba de arromba em que todas essas gentes se alegraram com muitas pândegas liberdosas. Então tudo acabou se fazendo a vida real. E os macumbeiros, Macunaíma, Jaime Ovalle, Dodô, Manu Bandeira, Blaise Cendrars, Ascenso Ferreira, Raul Bopp, Antônio Bento, todos esses macumbeiros saíram na madrugada. (ANDRADE, 2008, p. 69)

Do time dos defensores da cultura popular, que de alguma forma trabalhavam para a sua valorização, temos o grande poeta Manuel Bandeira; o crítico, fundador de revistas, poeta e romancista francês Blaise Cendrars; o poeta pernambucano Ascenso Ferreira; o jornalista, diplomata e escritor Raul Bopp; e o crítico de arte Antônio Bento. Aqui, para realçar a importância dos nomes citados no parágrafo, Mario de Andrade retorna com a vírgula para afirmar através de sua função o destaque necessário de tais individualidades.

Do lado dos boêmios e malandros que eram considerados figuras de enorme destaque naquela época, Mario de Andrade apresenta os dois mais representativos: Jaime Ovalle e Dodô (Geraldo Barrozo do Amaral), figuras que dividiam a mesa de bar não só com os intelectuais que aparecem no texto, mas também com pessoas da estirpe de Gilberto Freyre, Sérgio Buarque de Hollanda, Villa-Lobos, Di Cavalcante, e tantos outros, como nos mostra Humberto Werneck no livro O santo Sujo - A Vida de Jayme Ovalle (2008).

Por retratar, então, no mesmo espaço de convívio a classe trabalhista elitizada (advogados, médicos, senadores), a classe trabalhista marginalizada (marceneiros, taifeiros, curandeiros), e os intelectuais que influenciavam o pensamento da época juntamente com os boêmios símbolos que ditavam as regras na sociedade embrionária do samba, este capítulo da Macumba destaca-se dos outros do livro, conseguindo traduzir diretamente o pensamento que Antônio Candido chamava a atenção no ensaio da "Dialética da Malandragem”, pois a percepção das relações humanas tomadas em conjunto aparece aqui num nível elevado, sem buscar o retrato pormenorizado realista, assim também como em Memórias de um Sargento de Milícias, mas alcançando ainda mais a fidelidade do movimento social que procurava compreender.

\section{Leituras possíveis do “Entre-Lugar do Discurso Latino-Americano” no capítulo “Macumba"}

Silviano Santiago sempre apontou a enorme importância dos modernistas em sua obra, em textos diversos como O Cosmopolitismo do Pobre: critica literária e critica cultural 
(2004), Vale Quanto Pesa: Ensaios sobre questões político-culturais (1982), Nas Malhas da Letra (1989), e, principalmente, no livro Uma Literatura nos Trópicos: ensaios sobre a dependência cultural (1978), onde encontramos o ensaio "Entre-Lugar do Discurso LatinoAmericano”, escrito em 1971, que abordamos nesta análise. Por isso, não é difícil descobrir similaridades de seu pensamento com a obra Macunaíma, de Mario de Andrade, tornando-se ainda mais óbvia esta convergência de ideias no capítulo "Macumba”.

Como explicamos anteriormente, Macunaíma busca no trabalho da mãe de santo Tia Ciata castigar seu inimigo Venceslau Pietro Pietra. Muitos estudos da obra, incluindo os do próprio Mario de Andrade, apontam no inimigo do "herói sem nenhum caráter” a tradução direta do estrangeiro, enquanto Macunaíma representa de modo excêntrico o povo brasileiro.

Se no discurso combatido pelo entre-lugar qualquer valor literário de nossas obras está diretamente relacionado à imitação de fontes e influências européias, temos no capítulo "Macumba” essa voz de que a força é sempre do produto estrangeiro, nunca nossa, como Macunaíma deixa claro no primeiro parágrafo ao dizer:“inda não tenho bastante força não, Macunaíma, refletiu.[...] Porém por causa de não ter força tinha mas era muito medo do gigante” (ANDRADE, 2008, p.60).

Porém, assim como exige Santiago no seu texto pela questão de retirar a Europa do centro dos padrões culturais e artísticos vigentes, resgatando a multiplicidade étnica e cultural da formação nacional, Macunaíma arma-se do samba - nossa melhor tradução de "cultura pura”, como apontavam os modernistas -, mais precisamente o espaço no qual ele nasce, o terreiro de Tia Ciata, para castigar seu inimigo. A surra pedida nessa macumba surte efeito, sendo a primeira vitória contundente de nosso herói em cima de Venceslau Pietro Pietra dentro do livro.

Nesse aspecto, vemos um reflexo do pensamento dos modernistas identificado por Silviano Santiago também no livro O Cosmopolitismo do Pobre: critica literária e critica cultural (2004), que buscam “inverter os valores e hierarquias em jogo, visando valorizar os objetos culturais periféricos que, na historia ou nas ciências européias, são de antemão desclassificados pelo centramento ou marginalizados por razões econômicas”. (SANTIAGO, 2004, p. 27).

Para representar esta mudança de centro, a primeira pessoa atingida pela força do samba que vai aparecer dentro da prática da macumba - com referências diretas ao ritmo, como por exemplo, a expressão "notas afobadas cheio de saltos difíceis”, que faz alusão à síncope, marcação rítmica deste estilo musical - é justamente uma polaca, que perde o 
controle de seus atos ao ser atingida pelo ritmo forte de nosso samba, como se percebe nesta citação:

\begin{abstract}
Ogã pelejava batendo tabaque pra perceber os ritmos doidos do canto novo, canto livre, de notas afobadas cheio de saltos difíceis, êxtase maluco baixinho tremendo de fúria. E a polaca muito pintada na cara, com as alças da combinação arrebentadas estremecia no centro da saleta, já com as gorduras quasi inteiramente nuas. Os peitos dela balangavam batendo nos ombros na cara e depois na barriga, juque! com estrondo. E a ruiva cantando cantando. Afinal a espuminha rolou dos beiços desmanchados, ela deu um grito que diminuiu o tamanhão da noite mais, caiu no santo e ficou dura. (ANDRADE, 2008, p. 65)
\end{abstract}

Então, através de um ritual parecido com o vodu, do qual a pancada levada pela mãe de santo do terreiro será sentida por Venceslau Pietro Pietra, o "herói de nossa gente" consegue sua vingança com direito as piores formas imaginadas de castigar um inimigo, apoiando-se deste espaço em que o samba é o mestre de cerimônias para perder o medo do estrangeiro através da imposição de sua força na surra antológica:

\begin{abstract}
Então foi horroroso o que se passou. Exu pegou três pauzinhos de erva-cidreira benta por padre apóstata, jogou pro alto, fez encruzilhada, mandando o eu de Venceslau Pietro Pietra vir dentro dele Exu pra apanhar. Esperou um momento, o eu do gigante veio, entrou dentro da fêmea, e Exu mandou o filho dar a sova no eu que estava encarnado no corpo polaco. O herói pegou uma tranca e chegou-a em Exu com vontade. Deu que mais deu. [...] Enfim roxo de pancada sangrando pelo nariz pela boca pelos ouvidos caiu desmaiando no chão. E era horroroso... Macunaíma ordenou que o eu do gigante fosse tomar um banho salgado e fervendo e o corpo de Exu fumegou molhando o terreno. E Macunaíma ordenou que o eu do gigante fosse pisando vidro atra-vés dum mato de urtiga e agarra-compadre até as grunhas da serra dos Andes pleno inverno e o corpo de Exu sangrou com lapos de vidro, unhadas de espinho e queimaduras de urtiga, ofegando de fadiga e tremendo de tanto frio. Era horroroso. E Macunaíma ordenou que o eu de Venceslau Pietro Pietra recebesse o guampaço dum marruá, o coice dum bagual, a dentada dum jacaré e os ferrões de quarenta vezes quarenta mil formigas-de-fogo e o corpo de Exu retorceu sangrando empolando na terra, com uma carreira de dentes numa perna, com quarenta vezes quarenta mil ferroadas de formiga na pele já invisível, com a testa quebrada pelo casco dum bagual e um furo de aspa aguda na barriga. (ANDRADE, 2008, p. 67-68)
\end{abstract}

Por isso, os mesmos intelectuais que aparecem no parágrafo final e que já foram explicados anteriormente, muitos deles ligados aos modernistas, acabam por confirmar esse processo antropofágico de Oswald de Andrade, que Silviano Santiago tanto exige para a quebra deste entre-lugar, pois todos eles visualizaram na defesa de nossa cultura, mais precisamente no objeto cultural do samba, a melhor forma de desconstruir não só as noções de unidade e de pureza - com todas as classes sociais fazendo parte da mesma prática da macumba -, mas também fazer deste objeto nossa afirmação diante de qualquer processo de colonização forçado. 


\section{Conclusão}

Ao abordar duas leituras distintas como a "Dialética da Malandragem”, de Antônio Candido, e “O Entre-lugar do Discurso Latino-Americano”, de Silviano Santiago, convergindo no mesmo espaço do capítulo “Macumba”, do livro Macunaíma, de Mario de Andrade, podemos perceber o quanto as duas teorias buscam o mesmo senso comum: a crítica ao pensamento institucionalizado, da qual Celia Pedrosa chama a atenção no seu livro Antonio Candido: A Palavra Empenhada (1994) na obra de Candido, e os ensaios apresentados no livro Leituras Críticas sobre Silviano Santiago (2008) organizado por Eneida Leal Cunha demonstram na obra de Santiago.

Se em Candido, essa quebra ocorre na tentativa de apresentar uma sociedade "livre de culpabilidade e remorso, de repressão e sanções interiores”, em Santiago temos sua afirmação como produto artístico próprio, mostrando que ela pode ter suas próprias representações artísticas sem a necessidade de ressoar outras obras que não pertençam ao nosso local.

Portanto, ficamos com Tia Ciata, Pixinguinha, “os macumbeiros, Macunaíma, Jaime Ovalle, Dodô, Manu Bandeira, Blaise Cendrars, Ascenso Ferreira, Raul Bopp, Antônio Bento”, e toda a sociedade embrionária do samba, justamente a sociedade que influencia essa vontade direta de quebrar pensamentos institucionalizados, a sociedade do advento dos modernistas, que constrói em seu espaço não só a convergência do pensamento de Candido e Santiago, mas, também, reafirma a nossa identidade nacional, que não é excludente, chamando até mesmo o estrangeiro no exercício antropofágico para fazermos "festa juntos comendo bom presunto e dançando um samba de arromba em que todas essas gentes se alegraram com muitas pândegas liberdosas” (ANDRADE, 2008, p.69).

\section{Referências}

ALMEIDA, Manuel Antônio de. Memórias de um Sargento de Milícias. São Paulo: Ed. Atelier Editorial, 2000.

ANDRADE, Mário de. Macunaíma: O herói sem nenhum caráter. 1 ed. Rio de Janeiro: Mediafashion, 2008.

ANDRADE, Oswald de. Ponta de lança. Rio de Janeiro: Civilização Brasileira, 1972.

ANTELO, Raúl. Antonio Candido y los estudios latinoamericanos. Pittsburgh: Instituto Internacional de Literatura Iberoamericana: Universidad de Pittsburgh, 2001. 
CABRAL, Sérgio. Pixinguinha, vida e obra. Rio de Janeiro: FUNARTE, 1978.

CANDIDO, Antonio. "Dialética da Malandragem (caracterização das Memórias de um sargento de milícias)" in: Revista do Instituto de estudos brasileiros, nº 8, São Paulo, USP, 1970, pp. 67-89.

CUNHA, Eneida Leal (org.). Leituras críticas sobre Silviano Santiago. Belo Horizonte: Editora UFMG; São Paulo, Fundação Perseu Abramo, 2008.

DERRIDA, Jacques. A estrutura, o signo e o jogo no discurso das Ciências Humanas. In: A escritura e a diferença. São Paulo: Perspectiva, 1995.

FOUCAULT, Michel. A arqueologia do saber. Tradução de Luiz Felipe Baeta Neves. 2. ed. Rio de Janeiro: Forense-Universitária, 1986.

MOURA, Roberto. Tia Ciata e a pequena África no Rio de Janeiro. Rio de Janeiro: Funarte, 1983.

PEDROSA, Célia. Antonio Candido: a palavra empenhada. São Paulo - Niterói: EDUSP EDUFF, 1994.

SANTIAGO, Silviano. O cosmopolitismo do pobre: crítica literária e crítica cultural. Belo Horizonte, Editora da UFMG, 2004.

SANTIAGO, Silviano. Uma literatura nos trópicos. 2. ed. Rio de Janeiro: Rocco, 2000.

SANTIAGO, Silviano. (Org). Glossário de Derrida. Rio de Janeiro: F. Alves, 1976.

SILVA, Marília T. Barboza da; OLIVEIRA FILHO, Arthur L. de. Filho de Ogum Bexiguento. Rio de Janeiro: FUNARTE, 1979.

SOUZA, Eneida Maria de, MIRANDA, Wander Melo (Org.). Navegar é preciso, viver: escritos para Silviano Santiago. Belo Horizonte: Editora da UFMG; Salvador: EDUFBA; Niterói; EDUFF, 1997.

TINHORÃO, José Ramos. Música popular: um tema em debate. 3. ed. revista e ampliada. São Paulo: Ed. 34, 1997.

WERNECK, Humberto. Santo sujo: a vida de Jayme Ovalle. Rio de Janeiro: Cosac Naify, 2008. 